\title{
Introduction and acknowledgements
}

In recent years there has been a flood of articles and books on the role of social capital or trust among economic actors. These works generally conclude that a high degree of trust and trustworthiness is an important key to achieve success in most, if not all, business endeavors.

Social capital may be considered a stage in how the human contribution to wealth creation has been understood historically. At first human labor was simply conceived of as a commodity, as manpower. As appreciation for the many unique human characteristics grew, and knowledge about the influence of each of them on worker productivity became clearer, manpower evolved into some sort of branded good that behaved like capital, human capital. Subsequently we came to know of the different modalities of human capital, from intellectual capital to emotional capital, and from cultural capital to social capital. Although social capital as a trait can be attributed to both individuals and groups, it could best be studied perhaps as a feature of the personality of a leader. A problem that one immediately encounters, however, is that social capital is morally ambivalent in its uses and effects: that is, social capital could equally serve the purposes of a mafia clan as those of a philanthropic NGO.

If business ethics is to be taken seriously, a way has to be devised in order to take stock of the 'moral value' generated by workers and firms. This moral value could then be related to the ends that employees and businesses jointly pursue, such as wealth-creation and the attainment of overall well-being. Several initiatives from both the public and the private sectors have arisen to capture this moral value: the elaboration of codes of conduct for professions and organizations; the provision of ethical training within firms; the institution of corporate ethics offices; the design of social, ethical and environmental standards and accounting systems; and the passing of enabling legislation such as the US Foreign Corrupt Practices Act or the US Federal Corporate Sentencing Guidelines and their counterparts in different countries the world over.

At times, however, these measures are perceived to be superficial and cosmetic, as mere publicity gimmicks. The deeper intentions of those who put them into effect are not trusted. Furthermore, global civil society certainly demands compliance with its just laws, but aside from that it also requires a strong commitment to values and integrity from workers, managers and firms. This is especially the case when individual and corporate actions do not violate - strictly speaking - any law, but are still nevertheless morally censurable. 
In other words, beyond mere legal compliance, business ethics needs to be institutionalized in such a way that it permeates even apparently isolated individual practices, eventually forming part of a particular organization's wider corporate culture.

This book responds to the aforementioned challenges of overcoming the moral ambivalence of social capital and integrating moral value operatively into corporate culture. It seeks to achieve these twin goals by grounding itself on an aristotelian anthropology and by proposing guidelines or indicators for effective moral capital management.

This volume on moral capital rests on two basic analogies. The first one deals with a parallelism between persons and firms or organizations of whatever type. Human beings may be studied, both structurally and operationally, as living units that could be divided into at least four major levels: actions, habits, a unique temperament or character, and a singular lifestyle or biography. Similarly, the organizations which human beings constitute may also be said to be comprised of certain products (goods and services), protocols or standard operating procedures, a distinctive corporate culture and a particular corporate history. As we shall later explain, there is a striking correspondence between each of the levels that make up a human being and those that are found in a firm: between a person's actions and a firm's products, between a person's habits and a firm's procedures or protocols, between a person's character and a firm's culture, and finally, between a person's lifestyle choice or biography and a firm's corporate history.

The second analogy refers to the excellence or virtue of each of the previously mentioned levels on the one hand, and a specific institution of capital on the other. Thus, the good in a person's actions or in a firm's products may be conceived of as the basic currency or asset of moral capital; the good in a person's habits or in a firm's protocols as the compound interest; the good in a person's character or in a firm's culture as an investment bond; and the good in a person's lifestyle choice or in a firm's corporate history as an estate or legacy.

The development of these two analogies gives rise to some very enlightening and fertile insights on the true nature and meaning of human work within organizations. I have tried to amplify these points on the basis of what Aristotle had to say in the Nicomachean Ethics regarding the constitution and dynamics of the human being, and on what modern economic thinkers have taught with reference to capital.

In the course of writing this book I've also had the chance to examine a handful of recent business stories in search of examples in moral capital management. Almost always, I've focused my analysis on the figure of the corporate leader, trying to gauge how his or her initiatives and responses to the 
ever-changing environment have resulted in the growth or diminution of moral capital in the individuals and in the firm under his care.

How could the decades of neglect in the selection, training and pay of US airport security screeners by contractors such as Argenbright and ITS have contributed to the September 11 tragedy? Regarding the Enron executives and their associates, why weren't the extraordinary human capital holdings that they possessed - ivy-league MBAs - sufficient to prevent them from falling into such gross errors of professional and ethical judgment? While accommodating every outstanding quality that conventional human capital can offer - especially in terms of professional training and competence - moral capital certainly seems to require something more, such as internal rectitude.

The significance of actions and products as the elementary units of value and measure of moral capital will be discussed within two contexts. In the first one we shall look into the experiences of Ford and Firestone, in their joint denial of responsibility over a series of deadly accidents related to the use of their products, the Explorer SUVs and the ATX and Wilderness series tires, respectively. In the second, we shall be following the Cantor Fitzgerald CEO, Howard Lutnick, as he tried to cope with the consequences of the World Trade Center attacks and readily assumed responsibility over the welfare and well-being of the families of the workers who had perished. To begin with, something as simple as taking his son to kindergarten saved his life.

Both Ford and Firestone certainly got themselves into serious legal and financial trouble over the hundreds of deaths and injuries resulting from tire blow-outs and SUV rollovers in the 1990s. To what extent was each of these corporations responsible for the accidents? What did each of them know regarding the safety risks of their products? When and where did they first take notice of them? How did these safety risks or manufacturing defects come about? And most important of all, what could each of these companies have done to avoid so much suffering and loss of life?

This long string of accidents has caused a fallout not only in the top management of both Ford and Firestone but also in their century-old partnership. Most of these negative consequences could have been avoided if only the companies had owned up to their responsibilities for their products and actions squarely and in a timely fashion.

Cantor Fitzgerald could probably have been the firm worst affected by the 9-11 attacks, having lost 70 per cent of its workers. Its CEO, Howard Lutnick, however, set aside his personal grieving and promptly took charge - so to speak - of the victims' families, which he began to address and consider his own. But why did he immediately drop the missing employees from the payrolls? Was he not being hypocritical in his leadership? 
In turn, personal habits and corporate procedures - which represent moral capital's compound interest - will be explained by way of Microsoft's history of antitrust suits.

As corporate vices go, Microsoft stands out for its serial abuse of market dominance. The continuous denial of these charges by its leaders, together with their lack of repentance, have only caused these faults to worsen, both in scale and in scope. This may be the reason why any remedy other than the courtordered structural break-up would always foreseeably fall short of its goal. Will the dragon from Redmond ever be slain or will it again just prove itself to be more powerful and cunning than its adversary?

The impact of personal character and corporate culture - the investment bonds of moral capital - will be shown through an analysis of Hewlett-Packard (HP)'s takeover attempt of Compaq Computers.

Normally, a clash of cultures could be expected each time a merger between companies is under way; but that often takes place between the acquiring firm and the one that is acquired. In this case, however, the merger triggered off a culture crisis in the heart of the acquiring company itself, HP. It was a no-holdsbarred standoff between the heirs of the founding families and the old guard, represented by Walter B. Hewlett, and the group of professional managers and investors who rallied around the figure of the current CEO Carleton (Carly) S. Fiorina. This strategic corporate move rapidly turned into a contest over who among the two major characters was more credible and trustworthy in his or her vision of the HP way. Although as a matter of fact, Fiorina did pull the merger through by a 'slim but sufficient margin', the jury is still out as to whether the combined company would actually be a success. What repercussions will this drastic change of direction in management imply for the HP way?

And lastly, lifestyle choices or personal biographies together with corporate histories - the estates of moral capital - will be considered through an account of the auditing firm Arthur Andersen's downfall and a revision of Jack Welch's record at GE.

Andersen had gone through incredibly rough sailing throughout the latter half of the 1990s. During that time, it seemed to have abandoned strict compliance measures with its auditing standards for short-term gains in other activities such as consulting. What followed was a rapid breakdown of its corporate reputation, and consequently, the flight of its clientele. Once the reputation of an auditing firm is gone, there is hardly anything left in it of value. It just may have taken Andersen's last American CEO, Joseph Berardino, too long to realize this fact.

Apart from Jack Welch, it would be hard to find anyone in the corporate world who would better fit the definition of a living legend. But historical revisionism has caught up even with the corporate world and Jack Welch's record at GE has now come under close scrutiny. Just how much truth is there behind 
the avowed success of Jack Welch's stint at GE? What was his real personal impact on the company? What impact did GE in turn have on Jack Welch's own personal life?

This whole project would not have come to light were it not for the help of some very special people and institutions. I owe my thanks in the first place to Professor Rafael Alvira, for his unwavering confidence in my work, and to the Instituto Empresa y Humanismo of the University of Navarre, for its unstinting support. I would also like to express my gratitude to Professor W. Michael Hoffman and to the Center for Business Ethics at Bentley College for having provided me with a very congenial environment to bring this work to conclusion. And lastly, I would like to thank Professor Joanne Ciulla of the Jepson School of Leadership at the University of Richmond, and Alan Sturmer, my editor, for their encouragement as well as for their invaluable comments and suggestions.

Alejo José G. Sison Elmbrook Cambridge, MA

4 September 2002 